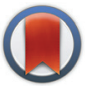

CrossMark $\leftarrow$ click for updates

Cite this: Dalton Trans., 2015, 44 2989

Received 20th November 2014, Accepted 7th January 2015

DOI: $10.1039 / \mathrm{c} 4 \mathrm{dt} 03574 \mathrm{~g}$

www.rsc.org/dalton

\section{Single ion magnet behaviour in a two-dimensional network of dicyanamide-bridged cobalt(II) ions $\uparrow$}

\author{
Joanna Palion-Gazda, ${ }^{a}$ Tomasz Klemens, ${ }^{a}$ Barbara Machura, ${ }^{\text {a }}$ Julia Vallejo, ${ }^{b}$ \\ Francesc Lloret ${ }^{\mathrm{b}}$ and Miguel Julve ${ }^{\mathrm{b}}$
}

\begin{abstract}
A novel two-dimensional coordination polymer of the formula $\left[\mathrm{Co}(\mathrm{dca})_{2}(\mathrm{atz})_{2}\right]_{n}$ (1) resulted from assembling trans-bis(2-amino1,3,5-triazine)cobalt(II) motifs by dicyanamide spacers. Variabletemperature dc and ac magnetic susceptibility measurements of 1 show that the high-spin cobalt(II) ions act as single ion magnets (SIMs).
\end{abstract}

In recent years, dicyanamide (dca)-bridged coordination compounds have attracted significant attention for their intriguing architectures and topologies as well as for a large variety of magnetic properties. ${ }^{1,2}$ The binary metal-dicyanamide complexes with a 3D-rutile type architecture $\left(\alpha-\left[\mathrm{M}(\mathrm{dca})_{2}\right]\right)$, formed by six-coordinate metal ions and three-connecting spacers ( $\mu_{1,3,5}$-dca ligands) in the $1: 2$ metal to dca molar ratio, exhibit a broad diversity long-range magnetic ordering at very low temperatures. ${ }^{3}$ This magnetic behaviour depends on the nature of the metal ion, being weakly ferromagnetic [Co(II), $\mathrm{Cu}(\mathrm{II})$ and $\mathrm{Ni}(\mathrm{II})]^{4}$ or spin-canted antiferromagnetic [ $\mathrm{Cr}(\mathrm{III})$, $\mathrm{Mn}(\mathrm{II})$ and $\mathrm{Fe}(\mathrm{II})]^{5}$ The modification of the M-dca networks by the incorporation of $\mathrm{N}$-donors as bridges or terminal coligands into the structures resulted in the formation of numerous architectures of the general formula $\left[\mathrm{M}(\mathrm{dca})_{2}(\mathrm{~L})_{n}\right](n=1$ or 2 ), including linear chains with a single or a double $\mu_{1,5}$-dca connectors, 2D $(4,4)$ nets and herringbone-like lattices with a single $\mu_{1,5^{-}}$dca bridge, triangular lattices with $\mu_{1,3,5^{-}}$and $\mu_{1,5^{-}}$ dca linkers, and also 3D networks. ${ }^{6-8}$ In contrast to the binary $\alpha-\left[\mathrm{M}(\mathrm{dca})_{2}\right]$ systems, the large number of magneto-structurally investigated heteroleptic compounds display very weak anti-

\footnotetext{
${ }^{a}$ Department of Crystallography, Institute of Chemistry, University of Silesia, 9th Szkolna St, 40006 Katowice, Poland. E-mail: basia@ich.us.edu.pl ${ }^{b}$ Departament de Química Inorgànica/Instituto de Ciencia Molecular (ICMol), Facultat de Quimica de la Universitat de València, C/Catedrático José Beltrán 2, 46980 Paterna, València, Spain. E-mail: miguel.julve@uv.es

$\dagger$ Electronic supplementary information (ESI) available: X-ray crystallographic data in CIF format, materials and methods, figures of XRPD, IR, UV-Vis and structure and crystallographic data (refinement conditions and bond lengths and angles) and a table of selected magneto-structural data of dca-bridged cobalt(II) complexes. CCDC 993408. For ESI and crystallographic data in CIF or other electronic format see DOI: 10.1039/c4dt03574g
}

ferromagnetic couplings ( $J$ less than $1 \mathrm{~cm}^{-1}$ ) because of the poor ability of the extended $\mu_{1,5}$-dca bridges to mediate electronic interactions. ${ }^{1 a, 2 e, 5 c, 7 a}$

Having in mind the recent research results dealing with a few magneto-structural studies of mono- and polynuclear Co(II) compounds where the metal ions exhibit slow relaxation of the magnetization behaving as single ion magnets (SIMs), ${ }^{9-12}$ we have used the dca anion and the 2-amino-1,3,5triazine (atz) molecule as a linker and an end-cap ligand, respectively. The resulting two-dimensional coordination polymer of the formula $\left[\mathrm{Co}(\mathrm{dca})_{2}(\mathrm{atz})_{2}\right]_{n}(\mathbf{1})$ has been characterized by spectroscopic techniques, X-ray diffraction and magnetic measurements.

Compound 1 was prepared $\$$ by the reaction of an aqueous solution of $\mathrm{Na}$ (dca) with a methanolic solution of $\mathrm{CoCl}_{2} \cdot 2 \mathrm{H}_{2} \mathrm{O}$ and 2-amino-1,3,5-triazine (atz) in a 2:1:2 dca:Co(II): atz molar ratio. Intense absorptions associated with the $\nu_{\text {as }}+$ $\nu_{\mathrm{s}}(\mathrm{C} \equiv \mathrm{N}), \nu_{\mathrm{as}}(\mathrm{C} \equiv \mathrm{N})$ and $\nu_{\mathrm{s}}(\mathrm{C} \equiv \mathrm{N})$, stretching modes of dca ligands occur at 2312, 2263 and $2194 \mathrm{~cm}^{-1}$, respectively. Their shift towards higher frequencies as compared to those of the sodium dicyanamide $\left(2286,2232\right.$ and $2179 \mathrm{~cm}^{-1}$ ) supports the coordination of dca in 1 . The XRPD pattern measured for the as-synthesized sample was in good agreement with the XRPD patterns simulated from the respective single-crystal X-ray data using the Mercury 2.4 program, ${ }^{13}$ demonstrating that the crystal structure is truly representative of the bulk material (ESI, Fig. S1 $\dagger$ ).

The single crystal X-ray analysis (see Table S1, ESI $\dagger$ ) revealed a polymeric structure consisting of neutral layers of the formula $\left[\mathrm{Co}(\mathrm{dca})_{2}(\mathrm{atz})_{2}\right]$ which are interlinked into a supramolecular 3D structure by hydrogen bonding between the coordinated atz ligands and the central nitrogen atoms of the dca bridges $\left[\mathrm{N}(4)-\mathrm{H}(4 \mathrm{~B}) \cdots \mathrm{N}(97)^{\mathrm{e}}\right.$ with values for $\mathrm{D} \cdots \mathrm{A}$ and $\mathrm{D}-\mathrm{H} \cdots \mathrm{A}$ of $3.083(3) \AA$ and $164.0^{\circ}$, respectively; symmetry code: (e) $=-1 / 2+x, 1 / 2+y,-1 / 2+z]$ (Fig. S2a $\dagger$ ) and $\pi-\pi$ stacking interactions with centroid-centroid distances of 3.573 and $3.744 \AA$ (Fig. S2b, ESI†).

Each cobalt(II) ion, located at the crystallographic inversion Wyckoff $4 \mathrm{~d}$ center, is six-coordinate with four nitrile nitrogen 
atoms at equatorial sites [Co-N distances of 2.0887(17) and 2.0968(16) $\AA$ ] and two nitrogen atoms of the atz ligand at the axial sites [Co-N distance of 2.1677(15) $\AA$ ] (see Table S2, ESI $\dagger$ ), building an elongated octahedron (Fig. 1a). The dca ligands adopt the $\mu_{1,5}$ bridging mode and they connect each metal ion to other four neighbouring metal centers leading to distorted rhombus-grid sheets parallel to the crystallographic $b c$ plane (Fig. 1b). The metal centers create 4-c uninodal net described by a $\left\{4^{2} ; 6^{2}\right\}$ Schläfli symbol and a [4.4.4.4.6(2).6(2)] extended point vertex symbol, which corresponds to the sql topological type. $^{14}$

Within the $[\mathrm{Co}(\mathrm{II})]_{4}$ units, the equatorial coordination planes of the neighboring metal centers are almost perpendicular, exhibiting a dihedral angle of $88.88^{\circ}$. The intralayer Co...Co separation through the dca bridge is $8.041 \AA$, whereas the metal-metal distances through the diagonals are different (13.423 and $8.859 \AA$ ), indicating that metal centers in the $[\mathrm{Co}(\mathrm{II})]_{4}$ units adopt a rhombus arrangement rather than a square disposition. Intralayer hydrogen bonds $[\mathrm{N}(4)-\mathrm{H}(4 \mathrm{~A})$ $\cdots \mathrm{N}(2)^{\mathrm{f}}$ with $\mathrm{D} \cdots \mathrm{A}=3.209(3) \AA$ and $\mathrm{D}-\mathrm{H} \cdots \mathrm{A}=174.0^{\circ}$; symmetry
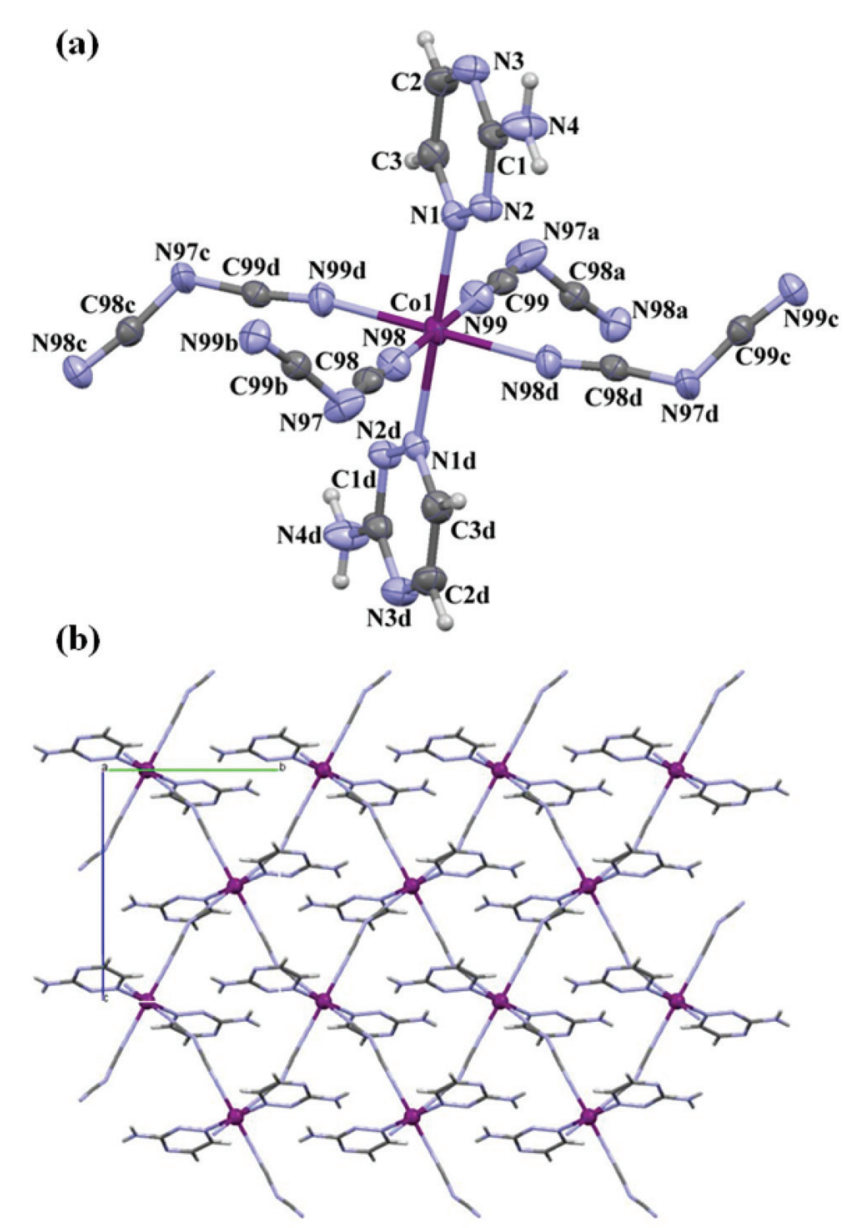

Fig. 1 (a) Perspective view of the metal environment in 1 together with the atom numbering. Displacement ellipsoids are drawn at $50 \%$ probability level [symmetry code: (a) $=x,-y,-1 / 2+z$; (b) $=x,-y, 1 / 2+z$; (c) $=1 / 2-x,-1 / 2+y, 1 / 2-z$; (d) $=1 / 2-x,-1 / 2-y, 1-z]$. (b) View of $a$ fragment of the $2 D$ structure of 1 formed by $\mu_{1,5}$-dca bridges. code: $(\mathrm{f})=1 / 2-x, 1 / 2-y, 1-z]$ contribute to the stabilization of the neutral layers. The shortest interlayer $\mathrm{Co} \cdots \mathrm{Co}^{\mathrm{g}}[\mathrm{sym}-$ metry code: $(\mathrm{g})=1 / 2+x, 1 / 2+y, z]$ separation is $8.602 \AA$.

The magnetic properties of 1 in the form of a $\chi_{\mathrm{M}} T$ versus $T$ plot $\left[\chi_{\mathrm{M}}\right.$ is the magnetic susceptibility per Co(II) ion] are shown in Fig. 2. At room temperature $\chi_{\mathrm{M}} T$ is equal to $2.77 \mathrm{~cm}^{3} \mathrm{~mol}^{-1}$ $\mathrm{K}\left[\mu_{\text {eff }}=4.71 \mathrm{BM}\right.$ to be compared with $\mu_{\text {eff }(\text { spin only } g=2.0)}=$ 3.87 $\mathrm{BM}$. This value is within the range of those observed for six-coordinate high-spin cobalt(II) complexes with an unquenched angular momentum. ${ }^{15}$ Upon cooling, $\chi_{\mathrm{M}} T$ remains practically constant in the high temperature range and it decreases sharply below $150 \mathrm{~K}$ to reach a value of $1.78 \mathrm{~cm}^{3} \mathrm{~mol}^{-1} \mathrm{~K}$ at $1.9 \mathrm{~K}$. No maximum of the magnetic susceptibility is observed in the $\chi_{\mathrm{M}} v s$. $T$ plot. The decrease of $\chi_{\mathrm{M}} T$ in 1 can be due to an antiferromagnetic interaction between the cobalt(II) ions and/or to the thermal depopulation of the higher energy Kramers doublets of the cobalt(II) centers.

Having in mind the previous magneto-structural results concerning the dca-bridged cobalt(II) compounds (see Table S3, ESI $\dagger$ ) and the large intra [ca. 8.0 $\AA$ across the single $\mu_{1,5}$-dca bridge] and interlayer [shortest value about $8.6 \AA$ ] cobalt-cobalt separation, the magnetic interaction between the local spin quartets, if any, is expected to be very weak. Consequently, the magnetic data of $\mathbf{1}$ were analysed through the Hamiltonian of eqn (1): ${ }^{16}$

$\boldsymbol{H}=-\alpha \lambda \boldsymbol{L}_{\mathrm{Co}} \boldsymbol{S}_{\mathrm{Co}}+\Delta\left[\boldsymbol{L}_{\mathrm{z}, \mathrm{Co}}^{2}-1 / 3 L(L+1)\right]+\beta H\left(-\alpha \boldsymbol{L}_{\mathrm{Co}}+g_{\mathrm{e}} \boldsymbol{S}_{\mathrm{Co}}\right)$

where $\lambda$ is the spin-orbit coupling and $\alpha$ is an orbital reduction factor defined as $\alpha=A \kappa$. The $\kappa$ parameter considers the reduction of the orbital momentum caused by the delocalization of the unpaired electrons and the $A$ parameter contains the admixture of the upper ${ }^{4} \mathrm{~T}_{1 \mathrm{~g}}\left({ }^{4} \mathrm{P}\right)$ state into the ${ }^{4} \mathrm{~T}_{1 \mathrm{~g}}\left({ }^{4} \mathrm{~F}\right)$ ground state $(A=1.5$ and 1 in the weak and strong crystal-field limits, respectively). $\Delta$ is the energy gap between the singlet ${ }^{4} \mathrm{~A}_{2}$ and doublet ${ }^{4} \mathrm{E}$ levels arising from the splitting of the triplet orbital ${ }^{4} \mathrm{~T}_{1 \mathrm{~g}}$ ground state under an axial distortion of the

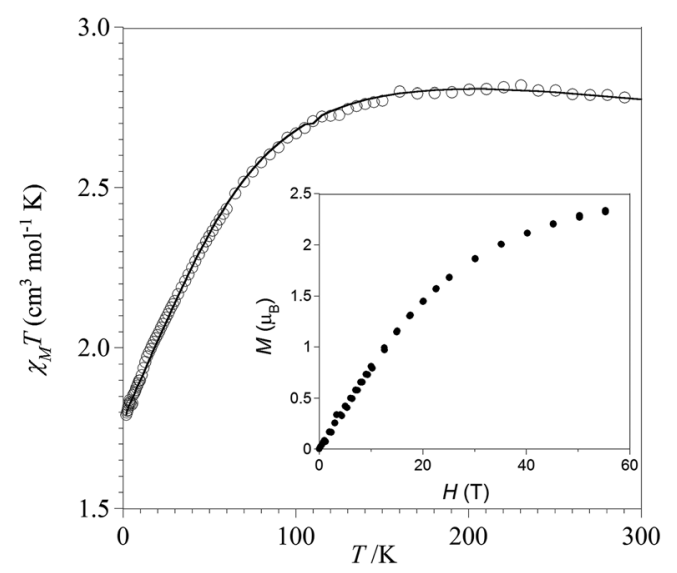

Fig. 2 Temperature dependence of the $\chi_{\mathrm{M}} T$ product for 1: (o) experimental; ( - ) best-fit curve through eqn (1) (see text). The inset shows the magnetization vs. $\mathrm{H}$ plot $2.0 \mathrm{~K}$. 
ideal $O_{\mathrm{h}}$ symmetry of the cobalt(II) ion. The best-fit parameters using the experimental data in the whole temperature range investigated are: $\alpha=1.18(1), \lambda=-125(1) \mathrm{cm}^{-1}$ and $\Delta=$ $-509(10) \mathrm{cm}^{-1}$. Given that the values of $D q\left(955 \mathrm{~cm}^{-1}\right)$ and $B\left(890 \mathrm{~cm}^{-1}\right)$ could be obtained through the analysis of the UV-Vis-NIR electronic spectrum of 1 (see Fig. S4, ESI $\dagger$ ), a value of $A=1.41$ can be calculated through eqn (2) and (3): ${ }^{16}$

$$
c=0.75+1.875 B / D q-1.25\left[1+1.8 B / D q+2.25(B / D q)^{2}\right]^{1 / 2}
$$

$$
A=\left(3 / 2-c^{2}\right) /\left(1+c^{2}\right)
$$

and then $\kappa$ is found to be equal to 0.84 .

The value of the magnetisation vs. $H$ plot for 1 at $2.0 \mathrm{~K}$ tends to a quasi-saturation value of $2.08 \mathrm{BM}$ at $6 \mathrm{~T}$ (inset of Fig. 2), a value which is as expected, $S_{\text {eff }}=1 / 2$ with $g_{\text {av }}$ ca. 4.2. In this respect, it deserves to be noted that the maximum value of the saturation magnetisation in the $M$ against $H$ plots $\left(M_{\text {sat }}=g_{0} \beta M_{\mathrm{S}}\right)$ as a function of the temperature $T<30 \mathrm{~K}$ [a situation where the ground doublet for a six-coordinate high-spin cobalt(II) ion is the only populated state] would be $2.06 \mathrm{BM}$ with $g_{0}=(10+2 \alpha) / 3=4.12$.

The ac susceptibility measurements for 1 under a $0 \mathrm{G}$ static field show no out-of-phase $\left(\chi_{\mathrm{M}}{ }^{\prime \prime}\right)$ signals suggesting a fast tunnelling of the magnetization (QTM). The application of a dc field of $1000 \mathrm{G}$ removes the QTM and the frequency dependence of $\chi_{\mathrm{M}}{ }^{\prime \prime}$ is observed (Fig. 3a). The relaxation times obtained from the maxima of $\chi_{\mathrm{M}}{ }^{\prime \prime}$ were fitted to an Arrhenius law (Fig. 3b), giving values for the energy barrier $\left(E_{\mathrm{a}}\right)$ and preexponential factor $\left(\tau_{0}\right)$ of $5.1 \mathrm{~cm}^{-1}$ and $1.7 \times 10^{-6} \mathrm{~s}$, respectively.

In conclusion, the X-ray structure of a novel $2 \mathrm{D}$ coordination polymer of the formula $\left[\mathrm{Co}(\mathrm{atz})_{2}(\mathrm{dca})_{2}\right]_{n}$ (1) with the cobalt(II) ions bridged by $\mu_{1,5}$-dca bridges has been reported. Combined dc and ac variable-temperature magnetic susceptibility measurements reveal the SIM behaviour of the magneti-

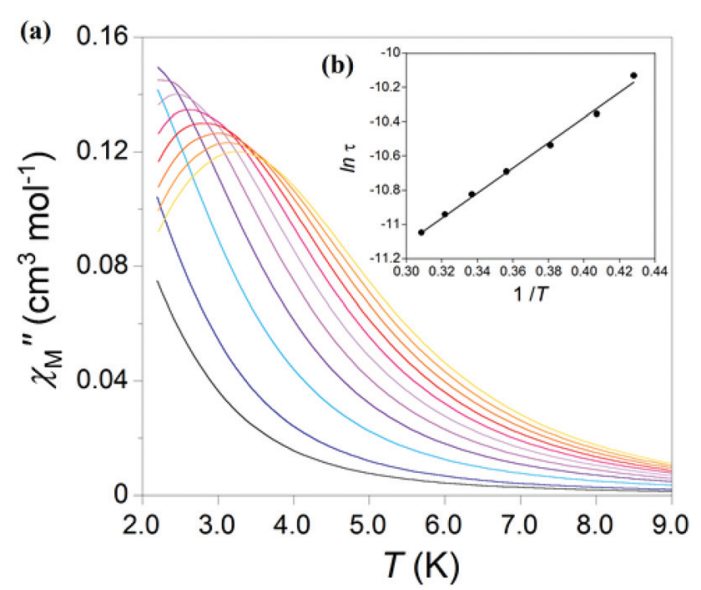

Fig. 3 (a) Frequency dependence of the out-of-phase ac susceptibilities from 2.0 to $9.0 \mathrm{~K}$ under a 1000 Oe dc field for 1 . (b) The relaxation time of the magnetization $\ln (\tau)$ against $1 / T$ for 1 . The solid line represents the Arrhenius plot. cally isolated six-coordinate high-spin cobalt(II) ions. Further work will be undertaken to increase the reduced number of magnetic coordination polymers of $\mathrm{Co}$ (II) behaving as SIMs by using the synthetic route described herein aiming to gain deeper insights into these interesting magnetic systems.

\section{Acknowledgements}

This work was supported by the Polish National Science Centre (grant no. 2012/07/N/ST5/02213), the Ministerio Español de Ciencia e Innovación (Project CTQ2013-44844P) and the Generalitat Valenciana (PROMETEOII/2014/070). Joanna Palion-Gazda is grateful for the scholarship from the DoktoRIS project co-financed by the European Social Fund.

\section{Notes and references}

† Synthesis: An aqueous solution $(5 \mathrm{~mL})$ of $\mathrm{NaN}(\mathrm{CN})_{2}(0.180 \mathrm{~g}, 2 \mathrm{mmol})$ was slowly poured into a methanolic solution $(15 \mathrm{~mL})$ containing $\mathrm{CoCl}_{2} \cdot 2 \mathrm{H}_{2} \mathrm{O}$ (0.240 g, $1 \mathrm{mmol})$ and 3-amino-1,2,4-triazine (0.192 g, $2 \mathrm{mmol})$ under continuous stirring for several hours. The resulting pink solution was filtered to remove any small solid particle and allowed to evaporate in a hood at room temperature. $\mathrm{X}$-ray quality pink prisms of $\mathbf{1}$ were grown from the mother liquor and collected after two weeks. Yield: $70 \%$ on Co. Elemental analysis (\%) for $\mathrm{C}_{10} \mathrm{H}_{8} \mathrm{~N}_{14} \mathrm{Co}(\mathbf{1})$ : Calcd: C, 31.34; H, 2.10; N, 51.17; Found: C, 31.52; H. 2.19; N, 51.99. IR (KBr, $\left.\mathrm{cm}^{-1}\right): 3400(\mathrm{~s}), 3319(\mathrm{~s})$ and $3215(\mathrm{~s})[\nu(\mathrm{NH})] ; 2311(\mathrm{~s})\left[\nu_{\mathrm{as}}+\nu_{\mathrm{s}}(\mathrm{C} \equiv \mathrm{N})\right] ; 2262(\mathrm{~s})$ $\left[\nu_{\text {as }}(\mathrm{C} \equiv \mathrm{N})\right]$ and $2194(\mathrm{vs})\left[\nu_{\mathrm{s}}(\mathrm{C} \equiv \mathrm{N})\right], 1631(\mathrm{~s}), 1586(\mathrm{w}), 1560(\mathrm{~m}), 1542(\mathrm{w})$ and $1527(\mathrm{w})[\nu(\mathrm{C}=\mathrm{N})]$ and $[\nu(\mathrm{C}=\mathrm{C})]$. UV-Vis-NIR (solid, nm): 1020, 427, 355, 302 and 217.

1 (a) S. R. Batten and K. S. Murray, Coord. Chem. Rev., 2003, 246, 103; (b) E.-Q. Gao, S.-Q. Bai, Z.-M. Wang and C.-H. Yan, Dalton Trans., 2003, 1759; (c) H.-L. Sun, S. Gao, B.-Q. Ma and S. R. Batten, CrystEngComm, 2004, 6(94), 579; (d) E. Colacio, J. Ruiz, A. J. Mota, M. A. Palacios, E. Ruiz, E. Cremades, M. M. Hänninen, R. Sillanpää and E. K. Brechin, C. R. Chim., 2012, 15, 878; (e) D. G. Branzea, L. Sorace, C. Maxim, M. Andruh and A. Caneschi, Inorg. Chem., 2008, 47, 6590; (f) A. M. Hardy and R. L. LaDuca, Inorg. Chem., 2009, 12, 308; $(g)$ G. S. Papaefstahiou, A. Escuer, F. A. Mautner, C. Raptopoulou, A. Terzis, S. P. Perlepes and R. Vincente, Eur. J. Inorg. Chem., 2005, 879; (h) L. Zheng, J. Chem., 2013, 291703.

2 (a) I. Dasna, S. Golhen, L. Ouahab, O. Peñs, J. Guillevic and M. Fetouchi, Dalton Trans., 2000, 129; (b) G. A. van Albada, M. E. Quiroz-Castro, I. Mutikainen, U. Turpeinen and J. Reedijk, Inorg. Chim. Acta, 2000, 298, 221; (c) A. Escuer, F. A. Mautner, N. Sanz and R. Vicente, Inorg. Chem., 2000, 39, 1668; (d) S. Martin, M. G. Barandika, J. I. R. de Larramendi, R. Cortés, M. Font-Bardia, L. Lezama, Z. E. Serna, X. Solans and T. Rojo, Inorg. Chem., 2001, 40, 3687; (e) J. Carranza, C. Brennan, J. Sletten, F. Lloret and M. Julve, Dalton Trans., 2002, 3164; (f) B. Vangdal, J. Carranza, F. Lloret, M. Julve and S. Sletten, Dalton Trans., 2002, 566. 
3 (a) S. R. Batten, P. Jensen, B. Moubaraki, K. S. Murray and R. Robson, Chem. Commun., 1998, 439; (b) P. Jensen, S. R. Batten, G. D. Fallon, B. Moubaraki, K. S. Murray and D. J. Price, Chem. Commun., 1999, 177; (c) M. Kurmoo and C. J. Kepert, New J. Chem., 1998, 22, 1515; (d) J. L. Manson, C. R. Kmety, Q.-Z. Huang, J. W. Lynn, G. M. Bendele, S. Pagola, P. W. Stephens, L. M. Liable-Sands, A. L. Rheiengold, A. J. Epstein and J. S. Miller, Chem. Mater., 1998, 10, 2552.

4 (a) C. R. Kmety, J. L. Manson, Q.-Z. Huang, J. W. Lynn, R. W. Erwin, J. S. Miller and A. J. Epstein, Mol. Cryst. Liq. Cryst. Sci. Technol., Sect. A, 1999, 334, 631; (b) C. R. Kmety, J. L. Manson, Q.-Z. Huang, J. W. Lynn, R. W. Erwin, J. S. Miller and A. J. Epstein, Phys. Rev. B: Condens. Matter, 1999, 60, 60; (c) T. Jestadt, M. Kurmoo, S. J. Blundell, F. L. Pratt, C. J. Kepert, K. Prassides, B. W. Lovett, I. M. Marshall, A. Husmann, K. H. Chow, R. M. Valladares, C. M. Brown and A. Lappas, J. Phys.: Condens. Matter, 2001, 13, 2263.

5 (a) J. L. Manson, C. R. Kmety, F. Palacio, A. J. Epstein and J. S. Miller, Chem. Mater., 2001, 13, 1068; (b) C. R. Kmety, Q. Huang, J. W. Lynn, R. W. Erwin, J. L. Manson, S. McCall, J. E. Crow, K. L. Stevenson, J. S. Miller and A. J. Epstein, Phys. Rev. B: Condens. Matter, 2000, 62, 5576; (c) S. R. Batten, P. Jensen, C. J. Kepert, M. Kurmoo, B. Moubaraki, K. S. Murray and D. J. Price, J. Chem. Soc., Dalton Trans., 1999, 2987; (d) A. Lappas, A. S. Wills, M. A. Green, K. Prassides and M. Kurmoo, Phys. Rev. B: Condens. Matter, 2003, 67, 144406.

6 (a) D. Ghoshal, A. K. Ghosh, J. Ribas, E. Zangrando, G. Mostafa, T. K. Maji and N. Ray Chaudhuri, Cryst. Growth Des., 2005, 5, 941; (b) B. W. Sun, S. Gao, B. Q. Ma and Z. M. Wang, Inorg. Chem. Commun., 2001, 4, 72; (c) J. L. Manson, A. M. Arif, C. D. Incarvito, L. M. LiableSands, A. L. Rheingold and J. S. Miller, J. Solid State Chem., 1999, 145, 369; (d) W. Dong, M. Liang, Y. Q. Sun and Z. Q. Liu, Z. Anorg. Allg. Chem., 2003, 629, 2443; (e) W. Guo, A. Escuer, M. Tang, C.-H. Jiang and M. Du, Inorg. Chim. Acta, 2013, 403, 142; (f) K. Bhar, S. Chattopadhyay, S. Khan, R. Krishna Kumar, T. K. Maji, J. Ribas and B. K. Ghosh, Inorg. Chim. Acta, 2011, 370, 492; (g) S. S. Massoud, M. M. Lemieux, L. Le Quan, R. Vicente, J. H. Albering and F. A. Mautner, Inorg. Chim. Acta, 2012, 388, 71; (h) A. Escuer, F. A. Mautner, N. Sanz and R. Vicente, Inorg. Chem., 2000, 39, 1668; (i) S. Dalai, P. S. Mukherjee, E. Zangrando and N. R. Chaudhuri, New J. Chem., 2002, 26, 1185; (j) J.-Y. Xu, C.-Z. Xie, F. Xue, L.-F. Hao, Z.-Y. Ma, D.-Z. Liao and S.-P. Yan, Dalton Trans., 2010, 39, 7159.

7 (a) D. Armentano, G. de Munno, F. Guerra, J. Faus, F. Lloret and M. Julve, Dalton Trans., 2003, 4626; (b) S. Konar, S. Dalai, P. S. Mukherjee, M. G. B. Drew, J. Ribas and
N. R. Chaudhuri, Inorg. Chim. Acta, 2005, 358, 957; (c) J. L. Manson, J. A. Schlueter and C. L. Nygren, Dalton Trans., 2007, 646; (d) R.-J. Wei, J. Tao, R.-B. Huang and L.-S. Zheng, Eur. J. Inorg. Chem., 2013, 916; (e) A. M. Kutasi, A. R. Harris, S. R. Batten, B. Moubaraki and K. S. Murray, Cryst. Growth Des., 2004, 4, 605; (f) S. Ghosh, S. Mukherjee, P. Seth, P. S. Mukherjee and A. Ghosh, Dalton Trans., 2013, 42, 10189.

8 (a) H. L. Sun, S. Gao, B. Q. Ma, G. Su and S. R. Batten, Cryst. Growth Des., 2005, 5, 269; (b) J. L. Manson, J. Y. Gu, J. A. Schlueter and H. H. Wang, Inorg. Chem., 2003, 42, 3950; (c) P. Jensen, S. R. Batten, B. Moubaraki and K. S. Murray, Dalton Trans., 2002, 3712.

9 (a) S. Gómez-Coca, E. Cremades, N. Aliaga-Alcaide and E. Ruiz, J. Am. Chem. Soc., 2013, 135, 7010; (b) R. Boca, J. Miklovic and J. Titis, Inorg. Chem., 2014, 53, 2367; (c) M. S. Fataftah, J. M. Zadrozny, D. M. Rogers and D. E. Freedman, Inorg. Chem., 2014, 53, 10716; (d) P. Cucos, F. Tuna, L. Sorace, I. Matei, C. Maxim, S. Shova, R. Gheorghe, A. Caneschi, M. Hillebrand and M. Andruh, Inorg. Chem., 2014, 53, 7738.

10 (a) T. Jurca, A. Farghal, P.-H. Lin, I. Korobkov, M. Murugesu and D. S. Richeson, J. Am. Chem. Soc., 2011, 133, 15814; (b) F. Habib, O. R. Luca, V. Vieru, M. Shiddiq, I. Korobkov, L. F. Chibotaru, S. Hill, R. H. Crabtree and M. Murugesu, Angew. Chem., Int. Ed., 2013, 52, 11290; (c) C. Rajnák, J. Titis, O. Fuhr, M. Ruben and R. Boca, Inorg. Chem., 2014, 53, 8200 .

11 (a) J. Vallejo, I. Castro, R. Ruiz-García, J. Cano, M. Julve, F. Lloret, G. De Munno, W. Wernsdorfer and E. Pardo, J. Am. Chem. Soc., 2012, 134, 15704; (b) V. Chandrasekhar, A. Dey, A. J. Mota and E. Colacio, Inorg. Chem., 2013, 52, 4554; (c) D. Y. Wu, X. X. Zhang, P. Huang, W. Huang, M. Y. Ruan and Z. W. Ouyang, Inorg. Chem., 2013, 52, 10976; (d) R. Herchel, L. Váhovská, I. Potocnák and Z. Travnicek, Inorg. Chem., 2014, 53, 5896.

12 (a) K. W. Galloway, M. Schmidtmann, J. Sánchez-Benítez, V. Kamenev, W. Wernsdorfer and M. Murrie, Dalton Trans., 2010, 39, 4727; (b) E. Burzurí, J. Campo, L. R. Falvello, E. Forcén-Vázquez, F. Luis, I. Mayoral, F. Palacio, C. Sáez de Pipaón and M. Tomás, Chem. - Eur. J., 2011, 17, 2818.

13 C. F. Macrae, I. J. Bruno, J. A. Chisholm, P. R. Edfinfton, P. McCabe, E. Pidcock, L. Rodríguez-Monge, R. Taylor, J. van de Streek and P. A. Wood, J. Appl. Crystallogr., 2008, 41, 466-470.

14 V. A. Blatov, A. P. Shevchenko and V. N. Serezhkin, J. Appl. Crystallogr., 2000, 33, 1193.

15 R. L. Carlin, Magnetochemistry, Springer-Verlag, Berlin, 1986.

16 F. Lloret, M. Julve, J. Cano, R. Ruiz-García and E. Pardo, Inorg. Chim. Acta, 2008, 361, 3432. 